\title{
DIAGNOSTIC ANALYSIS OF SILICON PHOTOVOLTAIC MODULES AFTER 20-YEAR FIELD EXPOSURE
}

\author{
M. A. Quintana, D. L. King, F. M. Hosking, J. A. Kratochvil, R. W. Johnson, B. R. Hansen \\ Sandia National Laboratories, PO Box 5800, Albuquerque, NM 87185 \\ N. G. Dhere and M. B. Pandit, Florida Solar Energy Center, 1679 Clearlake Rd., Cocoa, FL 32922-5703
}

\begin{abstract}
The objective of this study was to investigate the technology used by Spectrolab Inc. to manufacture photovoltaic modules that have provided twenty years of reliable service at Natural Bridges National Monument in southeastern Utah. A field survey, system performance tests, and a series of module and materials tests have confirmed the durability of the modules in the array. The combination of manufacturing processes, materials, and quality controls used by Spectrolab resulted in modules that have maintained a performance level close to the original specifications for twenty years. Specific contributors to the durability of the modules included polyinyl-butyral (PVB) encapsulant, expanded metal interconnects, silicon oxide anti-reflective coating, and excellent solder/substrate solderability.
\end{abstract}

\section{INTRODUCTION}

Over twenty years ago the Department of Energy and the Department of Interior agreed to install the world's largest, at the time, photovoltaic system at Natural Bridges National Monument (NBNM), managed by the National Park Service [1]. The system was to provide all electrical power to the park. Individual PV arrays manufactured by Spectrolab Inc., ARCO Solar, and Motorola were installed at NBNM in 1980 and are shown in Figure 1. Technology varied but all modules were monocrystalline silicon and all three module-types were representative of JPL Block III or earlier

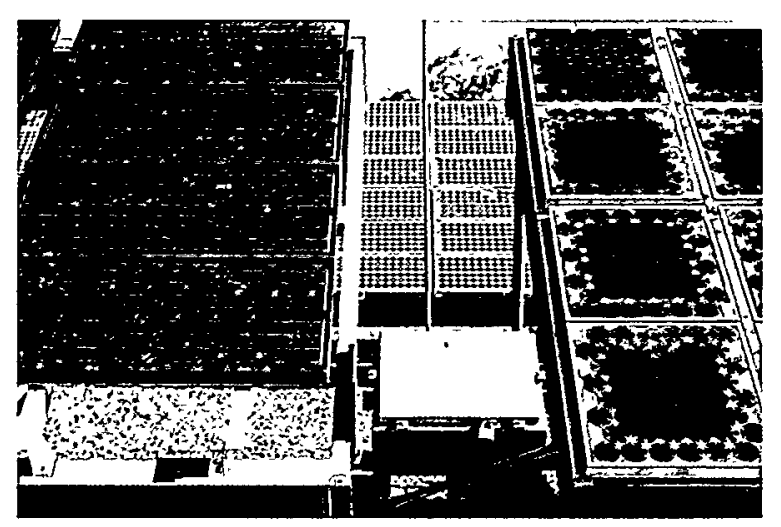

Fig. 1. Three arrays at NBNM include the Spectrolab array in the background. classification. Recently, arrays manufactured by Motorola and ARCO were disabled or dismantled due to increased maintenance requirements and/or significantly decreased power production. While additional arrays with newer technology have been recently added to the NBNM system, the original Spectrolab array continues to provide useful power to the park.

The Spectrolab array consisted of ten strings of 70 Block II modules nominally rated at $28.5 \mathrm{~W}$ at $1000 \mathrm{~W} / \mathrm{cm}^{2}$ and $41^{\circ}$ NOCT [2]. NBNM system performance tests sponsored by Sandia in 1985, 1992, and 1997 repeatedly showed that the array strings, while degrading in total output power, continued to maintain the shape of their I-V curves well and maintained high fill factors of about $70 \%$. A single field-aged module and two unexposed modules were studied to determine the technological reasons for this success.

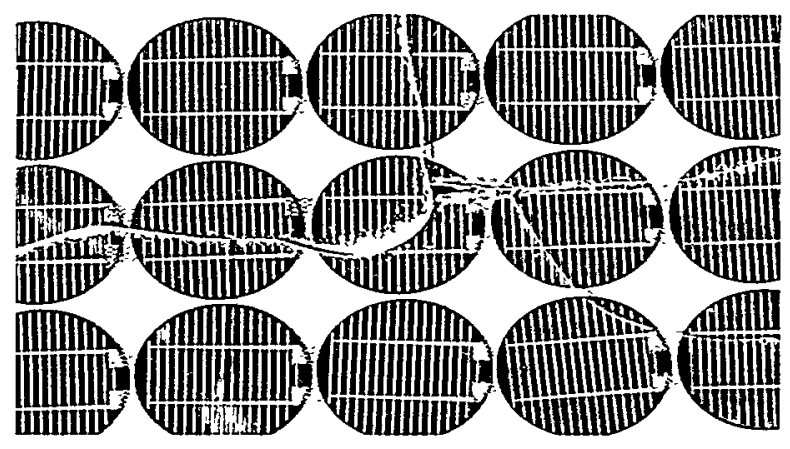

Fig. 2. Glass breakage and delamination on Spectrolab module

\section{FIELD OBSERVATIONS}

A field survey of the NBNM array was performed in 1999 and a Spectrolab module was obtained for diagnostic work. Later, two unexposed modules were obtained from NBNM for comparative electrical performance testing. The laminates were constructed with a single untempered-glass sheet, PVB encapsulant, 120 (5-cm diameter) $\mathrm{c}-\mathrm{Si}$ cells, another layer of PVB, and a Mylar@ backsheet. The backsheet of the modules were painted white to enhance the amount of light reflected back onto the cells [3].

Notable features in the array included a significant number of modules with cracked glass, Figure 2, 


\section{DISCLAIMER}

This report was prepared as an account of work sponsored by an agency of the United States Government. Neither the United States Government nor any agency thereof, nor any of their employees, make any warranty, express or implied, or assumes any legal liability or responsibility for the accuracy, completeness, or usefulness of any information, apparatus, product, or process disclosed, or represents that its use would not infringe privately owned rights. Reference herein to any specific commercial product, process, or service by trade name, trademark, manufacturer, or otherwise does not necessarily constitute or imply its endorsement, recommendation, or favoring by the United States Government or any agency thereof. The views and opinions of authors expressed herein do not necessarily state or reflect those of the United States Government or any agency thereof. 


\section{DISCLAIMER}

Portions of this document may be illegible in electronic image products. Images are produced from the best available original document. 
presumably due to hail damage or thermal cycling. A study performed shortly after the installation identified twenty-five cracked modules. It was hypothesized that the cracks occurred due to flaws along the edges of the glass in conjunction with excessive tensile stress caused by diurnal temperature cycling [4]. NBNM, located in southeastern Utah, has a climate that is hot and dry in the summer and cold and dry in the winter. Our field survey noted that despite the cracks in the glass surface of several modules and, in some cases missing glass shards, there was minimal delamination or corrosion caused by air and/or water intrusion. The encapsulant in a majority of the modules had yellowed to varying degrees. Some modules had nonuniform yellowing while a small fraction had no yellowing at all. Yellowing was initially attributed to moisture penetration at the glass fracture lines [4]. However, the field-aged module (20 years) used in this study was nonuniformly yellowed and the glass had not been fractured.

\section{TEST RESULTS}

The three Spectrolab modules were subjected to electrical performance tests, dark I-V tests and infrared thermal scans. Table 1 shows a summary of module electrical performance parameters. Electrical performance of the field-aged module was consistent with JPL Block II module specifications adjusted for temperature and solar spectrum. In a more direct comparison, performance of the field-aged module was about $10 \%$ lower than the two unexposed modules. A closer analysis shows that $l_{s c}$ on the aged module is $\sim 7 \%$ lower than that of the unexposed modules. This was attributed to an optical loss, likely from the yellowing of the encapsulant. The remaining loss in power, $\sim 2.5 \%$, resulted from decreased fill factor. The $V_{o c}$ of the fieldaged module remained unchanged suggesting that the fundamental performance of the silicon cells has remained stable. A 1997 system assessment showed that five of the ten module strings at NBNM were still performing at $\sim 80 \%$ of their initial field rating. Performance of the entire array had degraded $\sim 50 \%$ from the initial rating. Degradation was attributed to specific problems such as complete failure of individual modules in strings. The field data for functional module strings

Table 1. Spectrolab module electrical performance; original JPL rating and Sandia data for 20-year module and two unexposed modules.

\begin{tabular}{|l|c|c|c|c|}
\hline & Isc (A) & Voc (V) & Pmp (W) & FF \\
\hline $\begin{array}{l}\text { JPL/Block II } \\
\text { Rating, NOCT }\end{array}$ & 1.88 & 21.9 & 28.5 & 0.69 \\
\hline $\begin{array}{l}\text { JPL Data at } \\
\text { ASTM-SRC }\end{array}$ & 1.96 & 23.9 & 33.3 & 0.71 \\
\hline $\begin{array}{l}\text { Aged module, } \\
20 \text { years }\end{array}$ & 1.91 & 23.6 & 31.8 & 0.70 \\
\hline $\begin{array}{l}\text { Unexposed } \\
\text { module, \#1 }\end{array}$ & 2.08 & 24.0 & 36.2 & 0.73 \\
\hline $\begin{array}{l}\text { Unexposed } \\
\text { module, \#2 }\end{array}$ & 2.04 & 23.8 & 34.7 & 0.72 \\
\hline
\end{tabular}

along with our assessment of individual modules suggests: 1) about half of string-level power loss can be attributed to module degradation, 2) the remainder of the string-level power loss was likely due to increased resistance in module wiring and terminations.

\section{INFRARED IMAGING AND DARK I-V}

An infrared (IR) scan of the field-aged module showed uniform heating of the three parallel cell-strings while a steady current of 4.4 amps was circulated through the forward-biased module. Cell temperatures ranged from about $27.0^{\circ} \mathrm{C}$ to a maximum of $29.2^{\circ} \mathrm{C}$. There was an absence of localized hot spots that could indicate high resistance solder-joints. IR scans of the unexposed modules showed comparable temperatures and thermal uniformity. Dark I-V tests of the field-aged module yielded a cell series resistance $\left(R_{s}\right)$ of $53 \mathrm{~m} \Omega$. This is higher than contemporary products, but consistent with modules made with small cells. The $R_{\mathbf{s}}$ of the two unexposed modules was $36 \mathrm{~m} \Omega$. The apparent $47 \%$ increase in $R_{s}$ of the fieldaged module over twenty years corresponds to a $2.5 \%$ drop in fill factor, consistent with I-V data in Table 1.

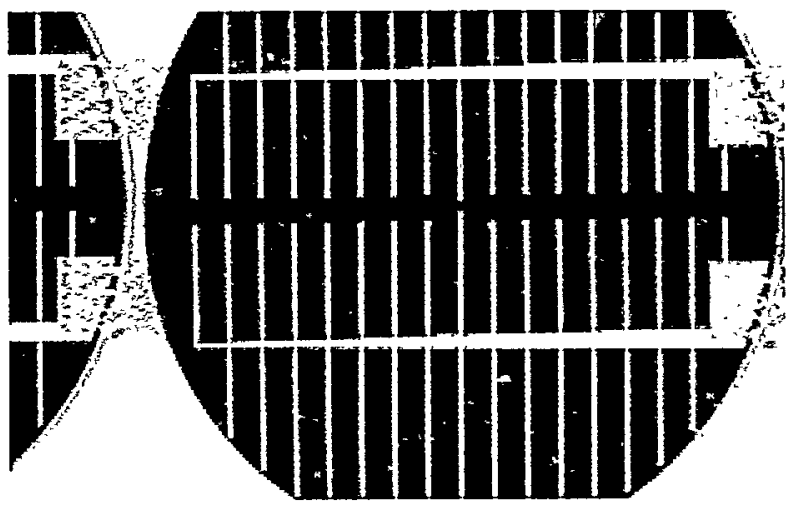

Fig. 3. Front-side solder joints and interconnects.

\section{SOLDER-JOINT METALLURGY}

Metallurgy of six solder-joint samples was examined by cross-sectioning and microanalysis. Interconnect material, Figure 3 , was similar to a material commonly known as "expanded metal". Expanded metal is a sheet or coil of metal that is slit and drawn into rows of diamond shaped openings. Spectrolab soldered these interconnects onto small pads on the cells rather than across the entire length of the cell. Multiple openings in the interconnect material provided a short escape path for

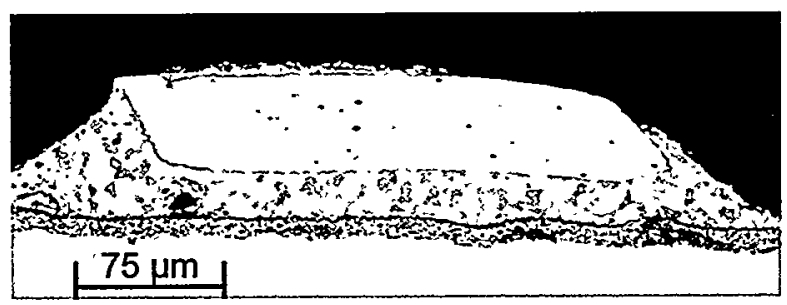

Fig. 4. Cross-section of solder-joint shows copper filament, solder, metallization, and silicon from top to bottom. 
gases generated during the soldering process, thereby minimizing voids. Voids have been identified as initiators frequently linked to solder-joint failure. Outgassing efficiency of the expanded metal interconnects may be an advantage over the solid ribbons currently used by the PV industry. Finally, soldering filaments rather than long lengths of flat ribbon also created a large number of transitional fillets that minimized stresses resulting from differential expansion. Sustained electrical performance over twenty years and metallurgical characteristics demonstrated the value of this interconnecting technique.

Grinding the joints to expose cross-sections was difficult because the width of interconnect filaments was small, 250-500 $\mu \mathrm{m}$ (.010-.020 in.). The cross-section of a solder-joint across the width of a filament in Figure 4 showed smooth transitional fillets. Joints studied had a small number of voids but no cracks. Cell metallization was thinner, 7-8 $\mu \mathrm{m}$, and uniform in thickness, indicating that the metallization was deposited through a very controlled process. Figure 4 shows a grainy, almost crystal-like structure in the metallization, suggesting that the metallization was screen-printed. The thin metallization and a well-controlled soldering process may have contributed to a small intermetallic layer. Excessive intermetallic reactions may contribute to solder dewetting and brittle joints. Solder-joints were uniformly thicker, 12$75 \mu \mathrm{m}$, than those observed in today's modules. Joints exhibited good wetting, suggesting clean surfaces, use of an effective flux, an effective soldering process, and good solderability of the substrate by the solder alloy.

\section{CELL TO ENCAPSULANT INTERFACE}

Characteristics of the cell to encapsulant interfaces were studied using adhesional strength tests, scanning electron microscopy (SEM), X-ray photoelectron spectroscopy (XPS), and Auger electron spectroscopy (AES) at the Florida Solar Energy Center (FSEC). Samples were cored using a 1.9-cm O. D. coring drill. Aluminum nuts were glued to the samples using an ultrahigh vacuum-compatible (UHV) conductive epoxy glue. The glue and relatively large sample diameter were required for XPS analysis. Forty samples, located from the periphery to the center, were extracted from twenty

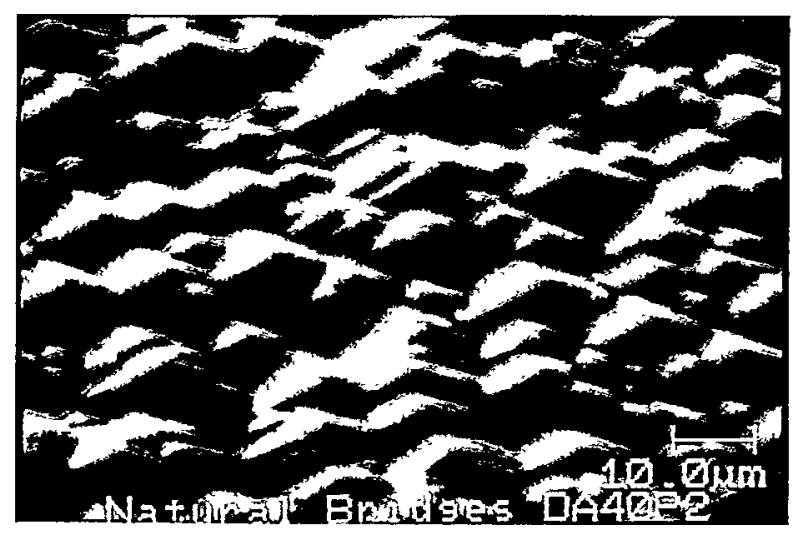

Fig. 5. SEM shows pyramidal texture on cell. cells. Samples were extracted by twisting, and a torque sensor was used to measure the force necessary to cause failure at the front cell/encapsulant interface. The average adhesional shear strength was $4.5 \pm 1$.0MPa. Baseline data on unexposed modules was unavailable but the measured values were about $80 \%$ of the adhesional strength of new modules made with EVA.

Twelve silicon cell samples were analyzed by Auger electron spectroscopy (AES), Table 2. Typically a spot between two gridlines was chosen for analysis. Figure 5 is a SEM micrograph that shows the surface texture of a cell. An AES survey was carried out on the cell surface over a range of kinetic energies from 50 to $2230 \mathrm{eV}$. An AES line-scan over a 102- $\mu \mathrm{m}$ length between gridlines, showed significant concentrations of potassium, sodium and tin distributed uniformly over the cell surface. Presence of tin and silver between gridlines was attributed to diffusion from the metallization over twenty years of service.

A depth profile, taken by sputtering the cell surface at a rate of $100 \AA$ per minute, showed the presence of $\sim 1650$ A thick silicon-oxide layer at the surface, Figure 6 . In addition, this analysis provided a better understanding of the impurities at the cell surface. Concentrations of sodium and tin decreased rapidly to negligible levels within a depth of $50 \AA$. The source of sodium is believed to be the glass superstrate. Concentrations of carbon and potassium fell slowly over a depth of $250 \AA$. The potassium peak reappeared and became more intense at the interface between the silicon-oxide and the elemental silicon. Presence of potassium was residue likely from the cell texturing process. As expected, phosphorous (n-type dopant) concentration near the silicon-oxide/cell interface was about $0.5-1$ atomic \%. Phosphorous was only present at negligible levels at the cell surface indicating it had not diffused through the silicon-oxide layer.

Table 2 AES survey of a Spectrolab cell lists impurities found on the surface.

\begin{tabular}{|l|c|c|}
\hline Element & $\begin{array}{c}\text { Kinetic Energies } \\
(\mathrm{eV})\end{array}$ & $\begin{array}{c}\text { Atomic } \\
\text { concentration (\%) }\end{array}$ \\
\hline \hline Silicon & $77,1548,1605$ & 61.8 \\
\hline Oxygen & 505 & 20.3 \\
\hline Carbon & 267 & 11.0 \\
\hline Sodium & 985 & 3.4 \\
\hline Potassium & 249 & 2.1 \\
\hline Tin & 421,431 & 1.1 \\
\hline Silver & 350 & 0.4 \\
\hline
\end{tabular}

Twelve PVB encapsulant samples were analyzed by XPS, Figure 7. The small amount of silicon on the encapsulant surface may have originated from a primer, if one was used to improve encapsulant adhesion, or from the silicon-oxide on the silicon cell. Silver and lead, both with atomic concentrations ranging from $0.1-0.5 \%$, were detected only on samples near the solder-joints. Presence of silver in an encapsulant sample was attributed to migration from the thick-film silver grid lines. 
Similarly, there were traces of lead, presumably from the solder-joint, on the encapsulant surface.

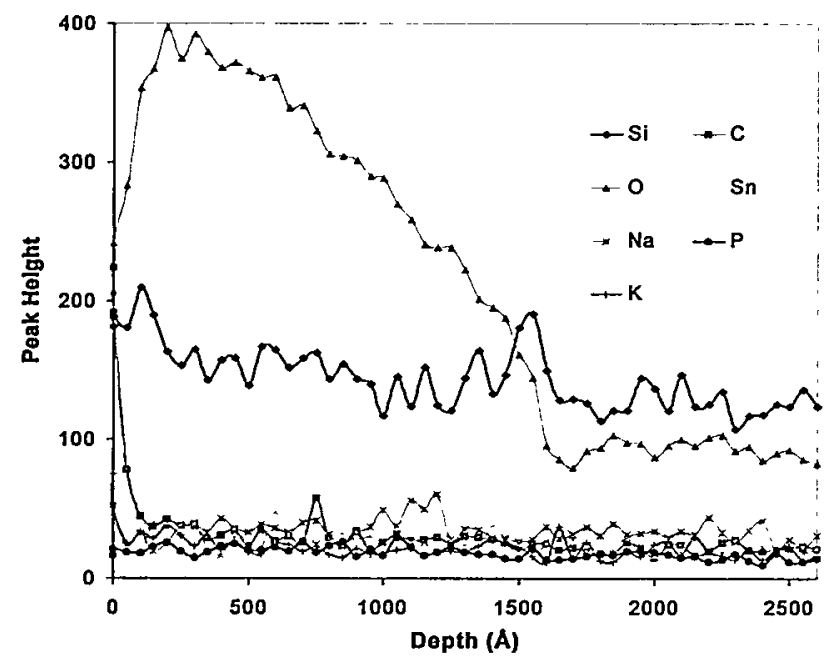

Fig. 6. AES depth profile of a c-Si sample

Low to moderate concentrations of impurities such as sodium, tin, potassium, silver, and lead were detected at the cell/encapsulant interface. The effect of potassium on adhesional characteristics is being investigated. Presence of $3-4 \%$ sodium and $1-2 \%$ tin may have reduced adhesional strength; however, encapsulant adhesion after twenty years was still nearly equivalent to unexposed EVA encapsulated modules currently manufactured. The factors that may have assisted in maintaining an adequate level of adhesional strength are: inert silicon-oxide AR coating, a thick and semiimpermeable painted Mylar ${ }^{\circledR}$ backing, and PVB encapsulant. In contrast, significant loss of EVA adhesional strength in field-deployed PV modules has been attributed to significant concentrations of phosphorous, sodium, titanium, and other impurities at the cell/encapsulant interface $[5,6,7]$.

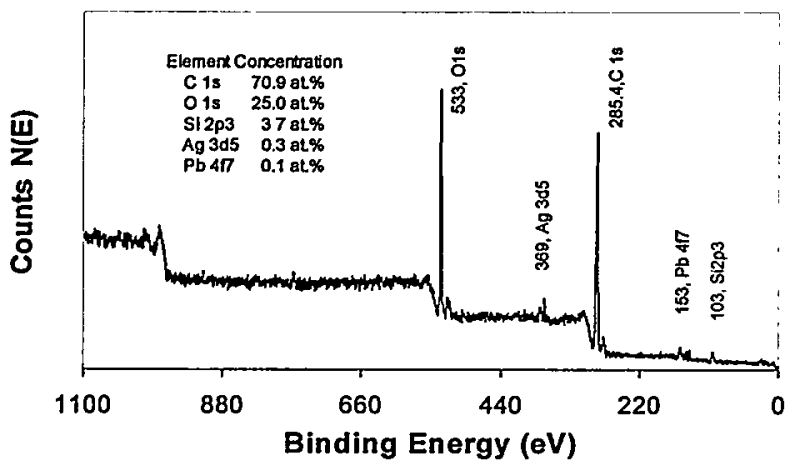

Fig. 7. XPS spectra of a PVB encapsulant sample

\section{CONCLUSIONS}

The Spectrolab array at NBNM recently completed twenty years of service with a high degree of module durability. National Park Service personnel are pleased with the array's performance and low maintenance. Results of our field survey and laboratory tests indicated that the array should continue to provide useful power to the park. Typical module degradation mechanisms such as delamination, corrosion, and solder-joint failure have not contributed to module degradation over twenty years. Using the unexposed modules as a baseline, we believe that the individual module output at NBNM has been degrading at a rate of about $0.5 \%$ per year. A high level of durability was achieved by using PVB encapsulant, a silicon-oxide AR coating, expanded metal interconnects, cell metallization with good solderabilty, and a compatible solder alloy. It is also important to recognize that even though module degradation rates were low, other factors resulted in a $2.5 \%$ per year array-level degradation. Clearly, degradation rates this high are still unacceptably high for future systems.

\section{ACKNOWLEDGEMENTS}

The authors are grateful to the staff at NBNM, especially Joe Joliet and Bob Lovato for their work and cooperation, and to Ken Ronney, Spectrolab Inc. for his historical perspective. Sandia National Laboratories is a multiprogram laboratory operated by Sandia Corporation, a Lockheed Martin subsidiary, for the U.S. Department of Energy under contact \#DE-AC04-94AL85000.

\section{REFERENCES}

[1] F. J. Solman, "The $100 \mathrm{kWp}$ Photovoltaic Power System at Natural Bridges National Monument", $15^{\text {th }}$ IECEC Conference, Seattle, WA, 18-22 August 1980

[2] M. I. Smokler, "User Handbook for Block II Silicon Solar Cell Modules", Jet Propulsion Laboratory, Oct. 1977

[3] Personal communication; Ken Ronney, Spectrolab Inc. [4] S. E. Forman, M. P. Themelis, "Reliability of Terrestrial Photovoltaic Modules at Various DOE/MIT Lincoln Laboratory Test Sites", $15^{\text {th }}$ IEEE PVSC, May 1981

[5] N. G. Dhere and N. R. Raravikar, "Adhesional Strength and Surface Analysis of a PV Module Deployed in Harsh Coastal Climate", Solar Energy Materials and Solar Cells, Proc. $11^{\text {th }}$ PVSEC, September 1999.

[6] N. G. Dhere, M. E. Wollam, and K. S. Gadre, "Correlation Between Surface Carbon Concentration And Adhesive Strength At The Si Cell/Eva Interface In A PV Module", Proc. 26th IEEE PVSC, Anaheim, CA, (1997), pp. 1217-1220.

[7] N. G. Dhere, K. S. Gadre, and A. M. Deshpande, "Durability Of Photovoltaic Modules", 14th European PVSEC, Barcelona, Spain, (1997), pp. 256-259. 